\title{
Delayed diaphragm recovery in 12 patients after high cervical spinal cord injury. A retrospective review of the diaphragm status of 107 patients ventilated after acute spinal cord injury
}

\author{
T Oo*, ${ }^{1}$, JWH Watt ${ }^{1}$, BM Soni ${ }^{1}$ and PK Sett ${ }^{1}$ \\ Regional Spinal Injuries Centre, Southport and Formby NHS Trust Hospital, Southport, Merseyside
}

\begin{abstract}
Study Design: The functional outcome of the diaphragm after acute spinal cord injury was reviewed over a 16 year period for 107 patients who had required assisted ventilation in the acute phase.

Objectives: To quantify the incidence of recovery of diaphragm function which occurred beyond the period of acute oedema; to produce a time-related profile of this as a guide to clinicians considering phrenic nerve pacing; and to assess the value of phrenic nerve testing in predicting recovery.

Setting: The Southport Regional Spinal Injuries Centre, Southport, England.

Methods: Bilateral phrenic nerve and diaphragm integrity was assessed clinically, by spirometry, and by fluoroscopy without and with phrenic nerve stimulation.

Results: Thirty-one per cent of all the ventilated patients (33 cases), with a level of injury between $\mathrm{C} 1$ and $\mathrm{C} 4$ (Scale A in ASIA Impairment Scale), had diaphragmatic paralysis at the time of respiratory failure. The subsequent diaphragm recovery which appeared in seven of these patients, between 40 and 393 days (mean 143), permitted weaning from ventilatory support at 93 to 430 days (mean 246) after the acute injury, with a vital capacity of over $15 \mathrm{ml} \mathrm{kg}^{-1}$ at that stage. The diaphragm recovery in a further five patients, whose vital capacity remained below $10 \mathrm{ml} \mathrm{kg}-1$ and who could not be fully weaned, occurred significantly later, between 84 and 569 days (mean 290), $P=0.053$. Negative phrenic nerve tests were followed by weaning at a later interval in several cases. By contrast, one patient with an early positive phrenic stimulation test and subsequent diaphragm activity could not be weaned from the ventilator.

Conclusion: Twenty-one per cent of the patients with initial diaphragm paralysis were ultimately able to breathe independently after 4 and 14 months, whilst a further $15 \%$ had some diaphragm recovery. Phrenic nerve testing should be repeated at 3 monthly intervals for the first year after high tetraplegia.
\end{abstract}

Keywords: tetraplegia; diaphragm function; phrenic nerve; mechanical ventilation; respiratory weaning; diaphragm pacing

\section{Introduction}

Respiratory failure after acute spinal cord injury (ASCI) may be due to total or partial respiratory muscle paralysis with fatigue of the spared muscles despite normal lung and chest wall compliance, or it may coexist with or be secondary to pulmonary, pleural or other pathology. In a review of respiratory complications after ASCI, in 261 patients with lesions between $\mathrm{C} 1$ and T12, Jackson and colleagues ${ }^{1}$ documented an overall incidence of respiratory complications of $67 \%$. The $\mathrm{C} 1-\mathrm{C} 4$ group had pneumonia in $63 \%$ of cases at a mean interval of 30 days post-injury and ventilatory failure in $40 \%$ at 3.5 days post-injury with a mean duration of $65.8 \pm 13$ days.

*Correspondence: Dr T Oo, Regional Spinal Injuries Centre, Southport and Formby NHS Trust Hospital, Town Lane, Southport, Merseyside PR8 6PN
It is possible to measure the vital capacity in the majority of patients with cervical injuries in the acute stage. Ledsome and Sharp ${ }^{2}$ measured the vital capacity (VC) sequentially in patients still breathing after cervical spinal damage and demonstrated a progressive improvement from 31.3 to $57.5 \%$ of that predicted between the first and 20th week. Severe reductions in $\mathrm{VC}$ may be associated with a fall in compliance, but measurement of the maximum inspiratory pressure or a neurological examination complement the assessment of the extent of respiratory muscle involvement. Patients with high level lesions associated with bilateral diaphragm paralysis cannot achieve and sustain a vital capacity of $5 \mathrm{ml} \mathrm{kg}-1$ without prior training and there is rarely doubt over the diaphragmatic muscle involvement from a clinical standpoint. 
Whilst there may be some early motor recovery with resolution of cord oedema, authors have chosen a time interval of either 1 month $^{3,4}$ or 6 weeks ${ }^{5}$ to chart further motor recovery. Although the restitution of spontaneous respiration after apnoea within the first year of ASCI is a quantal leap in terms of recovery, there have been few reports of this. McKinley's patient recovered diaphragmatic function between 8 months and 5 years and in his review he pointed out that whereas axonal regeneration would take over 12 months, neurapraxic recovery would happen in about 6 weeks. ${ }^{6}$ The three patients studied by Lieberman demonstrated the fluctuating responsiveness of the phrenic nerves within the first 4 weeks after injury, but the mean final recovery time on serial testing of the three pairs of diaphragms was $75 \pm 68.6$ days. $^{7}$

It had become apparent in the Southport experience that the incidence of recovery of the diaphragm in high, Frankel A, tetraplegic patients in the period beyond 1 month was greater than might have been expected and it was felt important to attempt to assess the pattern of what might loosely be termed a delayed recovery. The retrospective review is intended to estimate the incidence of delayed recovery and to recommend a frequency for systematic diaphragm reassessment before embarking upon the planning for a programme of domiciliary ventilation or for phrenic nerve stimulator implantation. The former requires much planning and both require major financial backing.

\section{Methods}

In the years from 1981 to 1996 in Southport, there have been 107 patients initially ventilated after acute spinal cord damage associated with trauma and who could be divided into three groups.

\section{Group 1}

Seventy-four patients with diaphragmatic preservation, including those with incomplete high level lesions were studied with respect to the time taken for ventilatory weaning.

\section{Group 2}

Twenty-one patients who had a permanent loss of voluntary diaphragm contraction (Table 2) had the viability of their phrenic nerves tested at various intervals after injury. Some of those with intact phrenic motor neurones later had phrenic nerve stimulator implantation. The time intervals of the phrenic nerve stimulation test and the phrenic nerve stimulator implantation were expressed as days from injury.

\section{Group 3}

Twelve patients with a complete lesion associated with diaphragm paralysis for at least 40 days following injury but with diaphragm recovery after that time.

Table 1 Patients with diaphragm recovery

\begin{tabular}{|c|c|c|c|c|c|c|}
\hline $\begin{array}{l}\text { Case no and } \\
\text { age at injury }\end{array}$ & Y.O.I & L.O.I. & $\begin{array}{l}\text { Last negative } \\
\text { diaphragm screen }\end{array}$ & $\begin{array}{l}\text { Phrenic nerve } \\
\text { stimulation }\end{array}$ & $\begin{array}{c}\text { Onset of } \\
\text { diaphragm recovery }\end{array}$ & Trache/outcome \\
\hline Case 1 (17) & 1981 & $\mathrm{C} 2$ & ND & ND & Day 40 & $\begin{array}{l}\text { No/Wean } \\
\text { (Day 94) }\end{array}$ \\
\hline Case 2 (30) & 1983 & $\mathrm{C} 4$ & Day 91 & ND & Day 211 & Yes/PTV \\
\hline Case 3 (31) & 1986 & $\mathrm{C} 2$ & Day 24 & ND & Day 216 & Yes/PTV \\
\hline Case 4 (34) & 1989 & $\mathrm{C} 2$ & Day 221 & Neg (day 221) & Day 393 & $\begin{array}{l}\text { No/Wean } \\
\text { (Day 430) }\end{array}$ \\
\hline Case 5 (14) & 1991 & $\mathrm{C} 3$ & Day 69 & Neg (day 69) & Day 569 & Yes/PTV \\
\hline Case 6 (7) & 1992 & $\mathrm{C} 3$ & Day 61 & Pos (day 61) & Day 121 & $\begin{array}{l}\text { No/Wean } \\
\text { (Day 192) }\end{array}$ \\
\hline Case 7 (28) & 1992 & $\mathrm{C} 4$ & Day 38 & Neg (day 38) & $\begin{array}{c}\text { Day } 57 \text { (left) } \\
\text { Day } 350 \text { (right) }\end{array}$ & $\begin{array}{l}\text { No/Wean } \\
\text { (Day 353) }\end{array}$ \\
\hline Case 8 (65) & 1992 & $\mathrm{C} 3$ & Day 243 & Neg (day 243) & Day 371 & Yes/PTV \\
\hline Case $9(56)$ & 1993 & $\mathrm{C} 2$ & Day 35 & Pos (day 35) & Day 84 & Yes/FTV \\
\hline Case 10 (34) & 1994 & $\mathrm{C} 3$ & Day 2 (USS) & ND & Day 50 & $\begin{array}{l}\text { No/Wean } \\
\text { (Day 93) }\end{array}$ \\
\hline Case 11 (36) & 1994 & $\mathrm{C} 2$ & Day 55 & Neg (day 55) & Day 141 & $\begin{array}{l}\text { Yes/Wean } \\
\text { (Day 406) }\end{array}$ \\
\hline Case 12 (23) & 1995 & $\mathrm{C} 3$ & ND & ND & Day 54 & $\begin{array}{l}\text { No/Wean } \\
\text { (Day 152) }\end{array}$ \\
\hline
\end{tabular}

$*$ Y.O.I. $=$ Year of injury; $*$ L.O.I. $=$ Level of injury; $*$ USS $=$ ultrasound scan; $*$ ND $=$ Not done; *Trache $=$ Tracheostomy;

$* \mathrm{PTV}=$ part-time ventilator dependant; $* \mathrm{FTV}=$ full-time ventilator dependant 
Table 2 Twenty-one patients with permanent diaphragm paralysis

\begin{tabular}{|c|c|c|c|c|}
\hline Case no and age at injury & Y.O.I. & L.O.I. & Phrenic nerve stimulation & Outcome \\
\hline Case A (16) & 1983 & $\mathrm{Cl}$ & Pos (day 35) & FTVD (PP-day 417) \\
\hline Case B (29) & 1983 & $\mathrm{C} 2$ & Pos (day 93) & FTVD (PP-day 266) \\
\hline Case C (18) & 1987 & $\mathrm{C} 2$ & Neg (day 3) & FTVD (IS-day 398) \\
\hline Case D (20) & 1988 & $\mathrm{C} 2$ & Pos (day 26) & FTVD (PP-day 391) \\
\hline Case E (4) & 1988 & C3 & Pos (day 350) & FTVD (PP-day 572) \\
\hline Case F (33) & 1989 & $\mathrm{C} 2$ & Pos (day 131) & FTVD (PP-day 246) \\
\hline Case G (3) & 1990 & $\mathrm{C} 2$ & Pos (day 127) & FTVD \\
\hline Case H (30) & 1990 & $\mathrm{C} 2$ & Neg (day 116) & FTVD \\
\hline Case I (6) & 1991 & $\mathrm{C} 2$ & Pos (day 34) & FTVD (PP-day 593) \\
\hline Case J (19) & 1991 & $\mathrm{C} 1$ & Pos (day 62) & FTVD (PP-day 566) \\
\hline Case K (57) & 1991 & $\mathrm{C} 2$ & Neg (day 91) & FTVD \\
\hline Case L (19) & 1992 & $\mathrm{C} 1$ & Pos (day 78) & FTVD (PP-day 400) \\
\hline Case M (3) & 1992 & $\mathrm{C} 2$ & Pos (day 72) & FTVD \\
\hline Case N (46) & 1993 & $\mathrm{C} 1$ & Pos (day 44) & FTVD (PP-day 266) \\
\hline Case O (4) & 1993 & $\mathrm{Cl}$ & Pos (day 68) & FTVD (PP-day 233) \\
\hline Case P (51) & 1994 & $\mathrm{C} 1$ & ND & FTVD \\
\hline Case Q (7) & 1994 & $\mathrm{C} 2$ & Pos (day 115) & FTVD \\
\hline Case R (1.5) & 1995 & $\mathrm{C} 1$ & Neg (day 96)/Pos (day 304) & FTVD \\
\hline Case S (14) & 1995 & $\mathrm{C} 3$ & Pos (day 195) & FTVD (PP-day 231) \\
\hline Case T (31) & 1996 & $\mathrm{C} 1$ & Neg (day 334) & FTVD \\
\hline Case U (17) & 1996 & $\mathrm{C} 1$ & Neg (day 186) & FTVD \\
\hline
\end{tabular}

$*$ Y.O.I. $=$ Year of injury; *L.O.I. $=$ Level of injury; $*$ FTVD $=$ Full time ventilator dependant; $* \mathrm{PP}=\mathrm{Phrenic}$ pacer; $* \mathrm{ND}=\mathrm{Not}$ done; *IS $=$ Intercostal stimulator

Patient 9 in this group sustained tetraplegia following neck traction associated with an undiagnosed cervical discitis (Table 1).

All time intervals of days are expressed as mean with standard deviations, but the range is included in some cases for ease of interpretation. The days of onset of diaphragm recovery were compared between those who weaned fully (group 3a) and those who weaned partially (group 3b) and analyzed for significance by the Mann-Whitney $U$-test.

The patient's vital capacities were measured in the supine position using a Wright's respirometer either at the mouth or attached to a catheter mount at the tracheostomy whilst preventing upper airway leaks. The movement of the right and left diaphragms in groups 2 and 3 was assessed fluoroscopically by asking the patient to attempt to breathe maximally, and then sniff without ventilatory support after preoxygenation. The excursion of the diaphragm was measured by a radio-opaque ruler placed on the patient's chest wall.

The phrenic nerve function was tested with the patient either sedated or under general anaesthesia without muscle relaxants. Supramaximal transcutaneous electrical stimulation was applied behind the sternomastoid muscle along the course of the phrenic nerve, at $1 \mathrm{~Hz}$, and the compound muscle action potential (CMAP) from the diaphragm contraction was recorded from surface electrodes attached to the chest wall over the insertion of the diaphragm at the seventh and eighth intercostal spaces in the anterior axillary line. At the same time the diaphragm excursion was assessed fluoroscopically.

\section{Results}

None of the patients were being administered centrally acting depressant drugs or neuromuscular blocking drugs which would have interfered both with clinical assessment and actual weaning. No patient had significant premorbid respiratory problems and none had any respiratory complication at the time of assessment.

The level of injury of the 73 patients in group 1 requiring ventilation ranged from $\mathrm{T} 12$ complete to $\mathrm{C} 0$ incomplete with diaphragm preservation. They were ventilated for periods of time ranging from 3-93 days, and were weaned after an average interval of $36.8 \pm 25$ days.

Twenty-one patients in group 2 with traumatic spinal cord damage at levels of $\mathrm{C} 0-\mathrm{C} 3$ have had no diaphragmatic recovery (Table 2). Fifteen of them had positive phrenic nerve stimulation tests at a mean time of 113 days, (range 26-350 days), and 11 of them went on to have phrenic nerve stimulator implantation after a mean time of 394 days (range 231-593 days) after the initial injury. No such patient has recovered spontaneous diaphragmatic activity since the implantation. The four remaining patients, or their parents, have elected against phrenic nerve pacing for the time being.

There were 11 males and one female in the group 3, ranging in age from 7-65 years, average 31.25 (Table 1), all with sensorimotor complete lesions, five patients with the level of injury $\mathrm{C} 2$, six patients with $\mathrm{C} 3$ and one patient with $\mathrm{C} 4$. Nine patients were ventilated on the first day of the injury, and two patients on the 
second day. Early respiratory parameters were not available before referral of the case 4 who had only required a tracheostomy for most of the initial 7 weeks before frank respiratory failure occurred on day 49 with confirmed diaphragm paralysis lasting another 344 days.

First signs of diaphragmatic recovery in all 12 patients within group 3 ranged between 40 and 569 days, $(199 \pm 165$ days). The mean time to recovery onset in the seven patients (group 3a) who become completely independent of ventilatory support was $143 \pm 116$ days compared with $290 \pm 186$ days in the five patients (group 3b) who remained partially ventilator dependant. With $U$ equals to 7 , the probability level for a significant difference between these two times was 0.053 .

Diaphragm paralysis in group 3 patients was documented by X-ray screening in nine, by ultrasound in one, and by clinical examination in two patients. Cases 2 and 5 had recovery of one diaphragm only, whilst the recovery of the diaphragms in case 7 was separated by 293 days. Diaphragm paralysis was not formally assessed in case 6 (age 7) at the time of the phrenic nerve stimulation, but clinically she was initially dependant on the use of accessory muscles during breathing exercises started 12 days later.

The time to full weaning in group 3a after recovery onset was $95 \pm 78$ days. The average VC of patients in group $3 \mathrm{a}$ after weaning was greater than $17 \mathrm{ml} \mathrm{kg}^{-1}$ (mean $22 \mathrm{ml} \mathrm{kg}^{-1}$ ) compared with $10 \mathrm{ml} \mathrm{kg} \mathrm{kg}^{-1}$ in group 3b. The individual values for VC and diaphragmatic excursions are shown in the Figure 1. Phrenic nerve stimulation (PNS) tests could be performed on seven patients but among the remain- der, three early cases were not tested and two other cases recovered before they were tested.

Of the patients who were later to wean fully, four had a negative PNS test $121 \pm 37$ days before the onset of recovery whilst a 7 year old girl tested positive 60 days before the actual clinical onset of diaphragmatic recovery.

\section{Discussion}

The review being retrospective in nature covers a period of 16 years over which time diagnostic practice has changed somewhat and not all cases had been submitted for diaphragm tests at the ideal times. Nevertheless, the substantial number of patients ventilated over this period of time warranted a formal estimation of the incidence of recovery after the first 40 days.

In Carter's retrospective study of 22 spinal cord injury patients with the level of injury $\mathrm{C} 4$ and below, who were identified having unilateral diaphragmatic paralysis, 16 of them had recovery of it after an average interval of 76 days, the longest duration for recovery being 14 months. The unilateral diaphragm paralysis and recovery were diagnosed and confirmed by fluoroscopy or double exposure chest X-ray. The onset of recovery was noted by the patient feeling stronger and dramatic improvement in the vital capacity. ${ }^{12}$

Whilst it is accepted that early oedema may cause a change in the neurological level within the first month, later recovery of previously paralysed diaphragms has tended to be unexpected as well as dramatic but reviews have not covered this vital neurological

\section{DIAPHRAGM AFTER RECOVERY}

GRG + VC

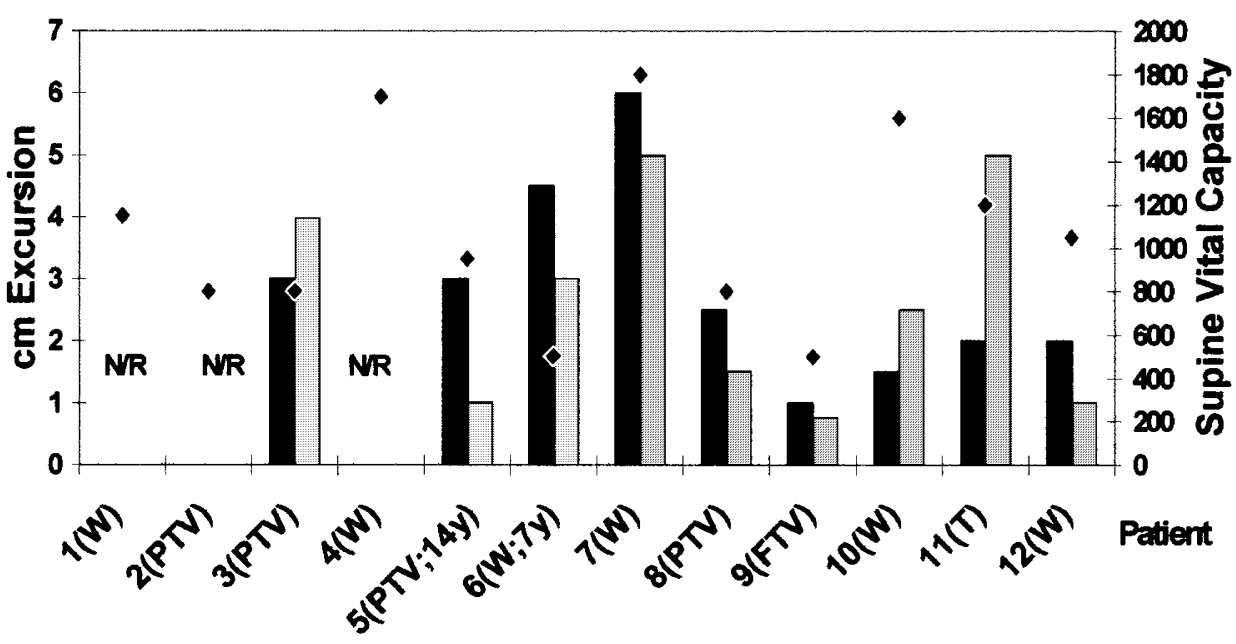

Figure 1 The vital capacities and right and left diaphragm excursions visualised fluoroscopically in the 12 patients in the period after diaphragm recovery $(\mathrm{W}=$ weaned; $\mathrm{PTV}=$ part-time ventilator dependant; FTV $=$ full-time ventilator dependant; $\mathrm{T}=$ weaned but with tracheostomy; patients 5 and 6 were 14 and 7 years of age) 
function perhaps because the ASIA Motor Score (ASIAMS) does not include the segments above C4. Clearly however, an expectation of such a significant recovery within a given period of time will influence the pace of the rehabilitation programme. The choice in this review of 40 days as a threshold for studies into delayed recovery is somewhat arbitrary but follows conventions in previous reports of neurological recovery. ${ }^{3-5}$ Furthermore though the inclusion in this study of case 1 (recovery observed on day 40) is borderline, it does help to illustrate the spread of time over which the diaphragm recovery may take place.

The degree of motor recovery (ASIAMS) between 1 month and 1 year in 61 patients with complete tetraplegia secondary to traumatic spinal cord injury was on average $8.6( \pm 4.7)$ in the study by Waters. ${ }^{4}$ Fifty-seven per cent of first zero grade muscles at 1 month had had some recovery, with $27 \%$ regaining greater than grade three strength, though in contrast only $1 \%$ of second zero-muscles regained strength equal to or greater than three at 1 year. The annualised rate of motor recovery flattens off markedly after 6 months though the recovery score continues to increase over the next $1-2$ years. There was no difference in these figures whether the level of lesion was at $\mathrm{C} 4, \mathrm{C} 5, \mathrm{C} 6$ or $\mathrm{C} 7$. The motor recovery in sensorimotor complete lesions in Bracken's study was 1.3 and 6.2 at 6 weeks, and 4.6 and 11.1 at 1 year for placebo and methylprednisolone respectively but the standard deviations for the recovery scores are not given and so it is difficult to know what functional improvement a typical patient may have had. ${ }^{4}$

If it is accepted that diaphragms are inervated from three cervical segments, then one might postulate that a weak bilateral diaphragmatic recovery be equivalent to a change in level from $\mathrm{C} 2-\mathrm{C} 3$ which would correspond to an improvement in the ASIAMS score of ten points. By contrast, diaphragmatic recovery sufficient for full weaning may correspond to a recovery of at least two segments, equivalent to 20 points.

With reference to Bracken's study one might indeed expect a significant proportionate recovery of diaphragmatic function in apnoeic patients with the C2/ C3 level of injury. Our figures suggest that this may be as high as $21.2 \%$ for patients whose diaphragm recovery was sufficient for weaning within 12 months, plus a further $15.2 \%$ for patients whose diaphragm recovery was insufficient for weaning at the end of 18 months. It is not possible to judge the effect of either age or methylprednisolone treatment (case 9) on the outcome in the present study.

All 12 patients were clinically stable in the period immediately before and after the observation of diaphragmatic recovery and were being ventilated on room air. They all had tracheostomies and so none required neuromuscular blocking agents or significant sedation.

Eight out of the 12 were engaged in a programme of accessory muscle training but this did not bear a relation to the actual outcome. The measurement of VC with a Wright's respirometer is a sensitive and repeatable ward test of the strength of breathing of the person with SCI. Adult patients with diaphragm paralysis who can be commenced on an accessory muscle training programme may only have an initial VC or around $50-100 \mathrm{ml}$. The accessory muscle training programme with graduated 'free-time' off the ventilator and incorporating documentation of the starting and finishing VCs did throw into sharp distinction the day in which the diaphragms recovered in some cases. Some patients recognised the change themselves, and staff observed the abdominal movements in others. The transition from accessory muscle to diaphragmatic breathing was continuous for case 6 in whom the diagnosis of diaphragmatic paralysis was clinically based until screened after weaning fully.

The weaning time might be expected to be partially influenced by the duration of paralysis since those recovering after prolonged paralysis have to regain diaphragm bulk, but other cases with weaning times markedly more prolonged than that for the group 1 may have had ongoing recovery of additional diaphragm motor units. In no case was there a delay in weaning attributable to pneumonia as defined by new and persistant infiltrates on the chest X-ray, grossly purulent tracheobronchial secretions, fever over $38.3^{\circ} \mathrm{C}$, leucocytosis and deterioration of pulmonary gas exchange. ${ }^{8}$

The range of diaphragmatic movement with respiration is over $3 \mathrm{~cm}$ in $77 \%$ of the normal population and though there is a certain amount of variability in the relative movement of the right and left side, the difference is usually less than $1 \mathrm{~cm} .{ }^{9}$ One feature in tetraplegia serves to make fluoroscopy of the diaphragm free of the pitfalls in the neurologically intact person due to the unintentional ability of the latter to contract and relax the abdominal musculature causing a passive shift in the position of the diaphragm. This can happen during the sniff test whereas the test is dependable in the patients with tetraplegia.

There is one report recommending EMG assessment of the diaphragm in the very early period after ASCI. ${ }^{10}$ An EMG amplitude of less than $50 \mathrm{mcV}$ was correlated with a VC less than $700 \mathrm{ml}$. Unfortunately, no patients in this category survived beyond 29 days making prediction of later outcome impossible. It would not be possible to draw any firm conclusions from amplitudes of the CMAP or nerve conduction times without frequent testing around the time of diaphragm recovery.

The diaphragm CMAP in response to phrenic nerve stimulation is better described after the acute phase of ASCI with recommendations for transcutaneous stimulation and the electropositive electrode at the seventh intercostal space, with the electronegative at the xiphoid process which produces an electropositive compound muscle action potential in the range $0.5-$ $1.0 \mathrm{mV} .^{11}$ These authors found only $8 \%$ could not 
tolerate the discomfort of the procedure and it is commonly our practice to administer light inhalational anaesthesia or sedation to allow for supramaximal stimulation.

A total of four of the group 3 patients who ultimately weaned completely had had negative PNS tests in the weeks or months preceeding and of two patients with positive results, one weaned fully but the other remained more or less ventilator dependant with diaphragmatic contraction only on recruitment with upper arm action. Those patients in this study who did ultimately wean having previously had a negative PNS test would in theory have had a positive result at or before the time of recovery. Such a recovery might be detected if PNS tests were undertaken at 3 monthly intervals for the first year.

The mean initial recovery time delay for group 3a was 134 days but their distribution was not normal with an outlier at 393 days. Though the statistical probability value barely reaches a significance level at 0.053 , there is a clinically significant difference in the mean time to recovery of those with late recovery who could be weaned, and those in whom weaning was only partially successful. Beyond 1 year the chances of recovery of fully independent breathing amount to probably less than $5 \%$ of patients with sensorimotor complete high tetraplegia and respiratory rehabilitation plans should be formalised by that time.

\section{References}

1 Jackson $\mathrm{AB}$, Groomes TE. Incidence of respiratory complications following spinal cord injury. Arch Phys Med Rehabil 1994; 75: $270-275$
2 Ledsome JR, Sharp JM. Pulmonary function in acute cervical cord injury. Am Rev Respir Desi 1981; 124: 41-44.

3 Waters RL, Adkins RH, Yakura JS, Sie I. Motor and sensory recovery following complete tetraplegia. Arch Phys Med Rehabil 1993; 74: $242-247$

4 Waters RL, Adkins RH, Yakura JS, Sie I. Effect of surgery on motor recovery following traumatic spinal cord injury. Spinal Cord 1996; 34: $188-192$

5 Bracken MB et al. A randomized controlled trial of methylprednisolone or naloxone in the treatment of acute spinal cord injury. $N$ Engl J Med 1990; 322: 1405 - 1411.

6 McKinley WO. Late return of diaphragm function in a ventilator-dependant patient with a high cervical tetraplegia; a case report and interactive review. Spinal cord 1997; 34: 622-629.

7 Lieberman JS et al. Serial phrenic nerve conduction studies in candidates for diaphragm pacing. Arch Phys Med Rehabil 1980; 62: $528-531$

8 Pingleton SK, Fagon JY, Leeper KV. Patient selection for clinical investigation of ventilator associated pneumonia. Criteria for evaluating diagnostic techniques. Chest 1992; 102 [Suppl 1]: $553-556$

9 Simon G. Principles of chest X-ray diagnosis. 3rd edn. Butterworths, London. 1971.

10 Lozes G et al. Nouvelle approche des quadriplegies traumatiques: L'electromyographie diaphragmatique. Ann Chir 1986; 40: $260-265$.

11 Markand AN et al. Electrophysiologic evaluation of diaphragm by transcutaneous phrenic nerve stimulation. Neurology 1984; 34: $604-614$.

12 Carter RE. Unilateral Diaphragmatic Paralysis in Spinal Cord Injury Patients. Parapletia 1980; 18: $267-273$. 